\section{EL DESCUBRIMIENTO DE LA DEMOCRACIA: LA MODERNIZACIÓN Y EL AGOTAMIENTO DE LA IMAGINACIÓN}

\author{
Julián Sauquillo \\ Universidad Autónoma de Madrid (UAM)
}

\author{
THE DISCOVERY OF \\ DEMOCRACY: THE \\ MODERNIZATION AND \\ EXHAUSTION OF IMAGINATION
}

\begin{abstract}
This article is a further study of the diagnostic of Modernity carried out by Alexis de Tocqueville. His criticism of the exhaustion of the imagination in the collective action with the emerging of the modern democracy enhances the contradictions of the contemporary world: a high level of welfare matches with the declining of the interest in public questions; the normalization of the behaviours and the administrative machinery taking possession of the public space of participation. Tocqueville and Mill start a critical diagnostic of the Modernity which will be followed by Weber and by the School of Frankfurt.
\end{abstract}

KEY WORDS: Tocqueville; Weber; Stuart Mill.

\section{LA CENTRALIZACIÓN ADMINISTRATIVA: \\ LA CONVERSIÓN DE LA POLÍTICA EN RUTINA}

La obra maestra de Tocqueville es un balance completo de las posibilidades y las aporías de la democracia moderna, que estaba surgiendo de manera inédita en Estados Unidos. Se convirtió en una obra de referencia para el diagnóstico de las aporías de la democracia moderna. El trágico diagnóstico de la burocratización del mundo moderno realizado por Weber es una prolongación brillante de la admonición tocquevilliana ante la posible conversión de la política en administración. La democracia en América $(1835,1840)$ y El Antiguo Régimen y la Revolución (1854) ${ }^{1}$ cierran un ciclo teórico de contraste entre los efectos sociales y políticos de la Revolución norteamericana y la Revolución francesa. Tocqueville obtiene una conclusión muy negativa de la confrontación entre la descentralización norteamericana y la centralización francesa. La centralización administrativa, iniciada por Luis XIV y heredada por los revolucionarios franceses, va a generar una suprema pasividad política entre los ciudadanos. Mientras la descentralización adminis-
RESUMEN: Este artículo indaga en el diagnóstico de la modernidad realizado por Alexis de Tocqueville. Su crítica del agotamiento de la imaginación en la acción colectiva, con la emergencia de la democracia moderna, subraya las contradicciones del mundo contemporáneo: un alto nivel de bienestar coincide con el declive del interés por las cuestiones públicas, la normalización de los comportamientos y el apoderamiento del espacio público de participación por la maquinaria administrativa. Tocqueville y Mill abren un diagnóstico crítico de la modernidad que será proseguido por Weber y la Escuela de Frankfurt.

PALABRAS CLAVE: Tocqueville; Weber; Stuart Mill.

trativa norteamericana -con centralización en las tareas de gobierno- impulsó una dinámica participación cívica en la "vida local", la centralización administrativa francesa se basó en la disolución de los comités locales, una vez se produjo la elección en los niveles provinciales y regionales. La revolución norteamericana, hasta cierto punto, es un contraejemplo para los revolucionarios franceses. Sieyès, por ejemplo, valoró como un infortunio para Francia que la Nación se hubiera fragmentado, tras la revolución, en una serie de Estados agrupados en torno a la Unión². Mientras que, para Tocqueville, por el contrario, la auténtica revolución es la norteamericana. La revolución francesa, en el análisis de éste, abolió las costumbres feudales y los cuerpos intermedios entre el individuo y el Estado, pero confirmó un modelo administrativo validado por Luis XVI. La "Revolución" es, dentro del diagnóstico de Tocqueville, la espuma sobrepuesta a una corriente acuífera subterránea que brota en el XVII Brumario de Napoleón Bonaparte y la Restauración francesa en 1800. Llama la atención la coincidencia de la filosofía de la historia de Tocqueville y Weber en la visión de las administraciones europeas como 
maquinarias estancas, tras las supuestas revoluciones burguesas. Para Weber, ni la administración francesa ni la administración zarista sufrieron cambios profundos tras sus respectivas revoluciones. En cambio, la Revolución norteamericana, sin instituciones del Antiguo Régimen que la precedan, plasma una democracia inédita que será el ejemplo y el futuro del viejo continente. Tocqueville refleja una disposición modernista mezcla de fascinación y terror ante los nuevos tiempos. Regresa de su viaje a Estados Unidos en 1831 con la novedad que atañe a Europa fundamentalmente: una política contemporánea realizada por hombres que no son santos, ni tampoco héroes, regirá la actividad del sistema democrático ${ }^{3}$. La política democrática con su igualitarismo democrático entierra la ya caduca excelencia de unos pocos regidos por las virtudes antiguas.

Mill, Tocqueville y Weber realizan la cartografía de las instituciones representativas en un período paradigmático de convulsiones sociales: los sucesos franceses de 18481851 y las agitaciones sociales de la República de Weimar, desarrollada entre 1919 y 1933, enfrentan a demócratas, nacionalsocialistas, liberales y socialistas. Aquellos tres son los artífices de una política reformista sustentada en la burguesía y en cuyas antípodas los dos primeros tienen como coetáneos a Marx y a Engels, y el último a Rosa Luxemburgo $0^{4}$ Marx, por su parte, escribe desde el exilio londinense de pensador nómada sus textos historiográfi$\cos$, desbrozando un amanecer revolucionario que premie el insomnio padecido por el cuarto estado. En La lucha de clases en Francia de 1848 a 1850 (1895), Marx fija el momento de la revolución en la contradicción entre las modernas fuerzas productivas y las formas burguesas de producción. Marx sitúa todos los episodios de 1848 y 1849 bajo la divisa de la derrota de la revolución ${ }^{5}$. Largo calvario le haria falta al partido de la subversión para sobreponerse a una contrarrevolución cerrada y potente. De forma más concluyente, Engels en el prólogo a esta obra -frente a la posterior opinión del espartaquismo alemán- señala el adelanto de las revueltas respecto al necesario acaecimiento de una crisis económica mundial y una mayor experiencia del ejército en la lucha callejera para aplacar las algaradas del pueblo como causas del fracaso de la insurrección del 48. Engels acaba prefiriendo la utilización estratégica de los instrumentos electorales legales a las movilizaciones sociales. Con escala de valores opuesta, Tocqueville observa, armado frente a "la pura canalla de la insurrección", la "confusión fraterna sin desorden" de las fiestas revolucionarias en los Campos de Marte, y describe la revolución en sus Recuerdos, sin populismo alguno ${ }^{6}$. La degradación de las costumbres públicas y la indignidad de los políticos para mantener el poder -según él-caldean el viento de revolución dado el empobrecimiento de la "vida pública". Mill coincidió con Tocqueville en ver en el empobrecimiento de la vida pública la causa ecuánime de la caída de Luis-Felipe. Marx busca la explicación económica de la política; Tocqueville y Mill otorgan, en cambio, a la política su sustantividad propia. Mientras Mill y Tocqueville priorizan las libertades formales para el futuro de la política, Marx no aprecia cambio político que no deba concluir en una liberación real'. Ambas posiciones reflejan la tensión entre una política revolucionaria y otra reformista -a veces crítica- que, hoy, heredamos decidida.

John Stuart Mill es clave para la reconstrucción del debate histórico entre liberalismo, democracia y socialismo en la politica moderna del siglo XIX. Mill, Tocqueville y Weber están unidos por la fascinación por la cultura política anglosajona -siempre diferenciada de la del viejo continente-, que surge con una novedad inaudita en Estados Unidos. En este vector teórico, Mill es un auténtico gozne en la reconstrucción de la teoría del liderazgo político de Alexis de Tocqueville y Max Weber. El "aire de familia" filosófico político que les asemeja se evidencia en ciertos rasgos compartidos por estas dos generaciones. En primer lugar, Mill escribió dos espléndidos comentarios a La Democracia en América $(1835,1840)$ en la London and Westminster Review, coincidiendo con su sucesiva aparición ${ }^{8}$. Allí, subrayó la importancia fundamental atribuida por Tocqueville a la actividad política realizada en el ámbito de la vida local. Pero, tanto en este comentario como en la correspondencia entre ambos, quedó patente el papel fundamental de las élites democráticas en el poder representativo del gobierno democrático americano. Además, Weber leyó a Mill y citó al escritor inglés en "La ciencia como vocación" (1919), con rasgos sumamente problemáticos de distanciamiento y de coincidencia fundamental: un precedente al que está lejos de alabar y otorgar razón, pero al que reconoce haber subrayado el valor ontológico del politeísmo en cuanto se sale de la pura empirea. En segundo lugar, por su vinculación con el modelo desarrollista de democracia, Mill y Tocqueville conciben la política como instrumento de desarrollo espiritual e intelectual de los individuos. Sin embargo, ambos tendrán que reflexionar frente a una antropología liberal 
precedente -el individuo maximizador de utilidades- que niega su modelo normativo de autorrespeto y perfección espiritual. El utilitarismo de Jeremy Betham y James Mill se adapta mejor a la descripción del comportamiento individual moderno como un cálculo egoísta para incrementar ventajas y beneficios. Consecutivamente, Weber representa una propuesta política in extremis de aceptación de la perversidad del mundo e intento de moralización de la vida política a través de la hercúlea tarea de un individuo carismático de cualidades heroicas. Mill conectó también con esta ética de la excelencia moral, a través de Carlyle y Tocqueville, por vía de Plutarco. En tercer lugar, los tres comparten la preocupación crítica frente a la conversión degradante de la política en una actividad rutinaria. Los tres observan críticamente la grave homogeneización propiciada por el mundo moderno y propugnan una dirección política del aparato burocrático. Ninguno de ellos acude a una fundamentación del poder en universales morales. A Weber nada le parecía más execrable que utilizar la ética para llevar razón. Tocqueville obvia las discusiones acerca de los principios generales en el día a día de la política y a Mill le preocupaba poco si la propiedad era un derecho natural o no a la hora de reconocer límites variables a este derecho. El politeísmo moral de Weber ya está presente en Mill, quien comparte con Tocqueville una teoría moral basada en la libertad. La explicación de todos ellos del poder es estratégica y no reducible al lenguaje de los derechos universales.

Desde tradiciones culturales muy distintas, los tres subrayan los males endémicos del proceso de racionalización del mundo moderno bajo las formas de centralización, organización racionalizadora, reducción de la vida a mera supervivencia o elusión del deseo al cálculo administrado. Tanto Tocqueville como Mill y Weber sitúan la acción social moderna bajo el dictum, posterior en el tiempo, de Adorno y Horkheimer, de crítica del contenido represivo de la igualdad: "el precio de la igualdad de todo con todo consiste en que nada puede ser idéntico a sí mismo. La ilustración disuelve el error de la vieja desigualdad pero (...) destruye lo inconmensurable (...)". La constricción moderna de la libertad en el interior de la weberiana "jaula de hierro" es debelada de la misma crítica forma en el frankfurtiano viaje de Odiseo. La mayor cientificidad y eficiencia de la máquina administrativa genera menos libertad. Nadie escapa a este poder acrecido del Gobierno moderno que, cuanto más se expande, más puede prescin- dir de las demandas sociales. Si el postulado reformador de Bentham era todavía organizar y moralizar a la administración racionalmente, la preocupación de Mill y Tocqueville es evitar su sobredimensionamiento. Ambos comparten la misma concepción de la libertad. Tocqueville le escribe a Mill en una de las últimas cartas: "Mi querido Mill, recibi ayer su libro Sobre la libertad. Me lo he encontrado en Cannes, donde mi salud me forzó a venir para pasar el invierno (...). Siento indudablemente a cada instante que sobre este terreno de la libertad no sabríamos marchar sin darnos la mano" (9 de febrero de 1859) ${ }^{9}$. Mill, influido por Tocqueville, temió los efectos homogeneizadores de aquel criterio en que Bentham fijó máximas esperanzas: el control político y moral de la "opinión pública". La tiranía de la opinión mayoritaria supondría necesariamente una opresiva limitación del alma individual ${ }^{10}$. De ahí que los rasgos más sobresalientes de la filosofía moral de Sobre la libertad (1859) reparen en la protección de la disidencia, el ideal del desarrollo de la individualidad no sometido al yugo social, la libertad de creación y expresión de una opinión incluso herética, y, en definitiva, la inexistencia de otro criterio de intervención estatal en la esfera de libertad civil y política que evitar un daño a terceros.

Del temor a la reducción absoluta de la política a administración surge el compromiso teórico y práctico de Tocqueville, Mill y Weber por una organización dinámica del monstruo burocrático. Para Aron, el problema central de Tocqueville es el desarrollo de uno de los problemas que plantea Montesquieu: el despotismo o poder arbitrario de uno solo es contrario a la libertad, mientras que una república o una monarquía moderada pueden proteger la libertad. Para Montesquieu, la desigualdad es garantía de libertad en la monarquía francesa. Pero, al estudiar la monarquía inglesa, se encuentra con una monarquía liberal, basada en la representación y la primacía de la actividad mercantil. Tocqueville desarrolla los análisis de Montesquieu sobre la monarquía inglesa, consciente de que aquí la libertad -a diferencia de lo que ocurría con la monarquía francesa- no requiere de desigualdad de condiciones ${ }^{11}$. Pero Tocqueville siente en carne propia cómo la aristocracia es un Gobierno indefectiblemente superado. Tal como señala Schmitt, Tocqueville es el pintor y moralista de una época que vive existencialmente como vencido. Su coraje intelectual y cortesía se sobreponen sobre una ruidosa desesperación ${ }^{12}$. Se desinteresa por viajar a Inglaterra porque los gobiernos mixtos le parecen sociológica e 
históricamente superados. Y, respecto de Francia, la experiencia americana reúne la ventaja de surgir sin revolución. América aporta una democracia en estado puro, incluso, en comparación con Inglaterra, a la que secunda. Los ingleses son aristócratas en Inglaterra y demócratas en Estados Unidos $^{13}$; Tocqueville abre así una firme inquietud por la vida norteamericana proseguida por Mill y Weber.

\section{La AMISTAd fRENTE a la "tiRANía de la mayoría": LA CORRESPONDENCIA ÍNTIMA COMO PROGRAMA POLÍTICO}

El viaje de Alexis de Tocqueville y Gustave de Beaumont a Estados Unidos, entre abril de 1831 y enero de 1832, requirió de cuarenta días de travesía. El viaje suponía una aventura alentada por el deseo de experimentar la emergencia de la democracia en el lugar mismo de aparición. Desconfiaban de principios teóricos absolutos para analizar la democracia y querían ver la democracia en su estado palpitante. Tocqueville no se encontraba seguro como juez en Versalles al poco de ser nombrado. Le desespera ser como un colegial que sale a la ciencia con una formación informe en la cabeza. A pesar de haber trabajado tanto como sus colegas juristas, es incapaz de ser el primero y satisfacer su orgullo. Además le cuesta hablar en público y no puede ni adornar, como otros, sus malos razonamientos jurídicos. Aunque el trabajo práctico de juez le satisface y se va concentrando, teme convertirse en una máquina silogística. Antes quema sus libros -confiesa- que convertirse en esa máquina (A Kergorlay, Versalles, 23/VII/1827) ${ }^{14}$. Quedaba así el camino expedito hacia América. El viaje de estos dos magistrados de Versalles se inscribe entre otros dos de La Rochefaucault-Liancourt y Chateaubriand anteriores, y otros posteriores de Bryce, Ostrogorski y Weber. Todos querian extraer experiencias e innovaciones norteamericanas que fueran provechosas para Europa. Estaba en juego la revisión de los presupuestos ilustrados y de la teoría de los derechos humanos como concepciones demasiado abstractas para organizar las instituciones públicas consecuentemente. Ciertamente, la amistad entre Beaumont y Tocqueville permaneció intacta hasta el final pero hubo un distanciamiento evidente entre ambos en torno al análisis del proceso moderno de democratización de la política. Era tan ambivalente e ineluctable para ambos el proceso democrático, tan diverso les resultaba, que se separaron en un proyecto inicialmente compartido de escribir juntos La democracia en América.

Ante los cambios sociales en la sociedad democrática, los hombres más distinguidos -dotados de virtudes excelentes, antiguas- vieron el poder social de la mayoría como el poder tiránico nuevo. Tocqueville y algunos de sus amigos sintieron el poder democrático como una nueva tiranía del Uno, en los términos de Étienne de La Boétie. Como ocurría ante la tiranía del monarca o de la aristocracia, la nueva tiranía democrática, surgida en Estados Unidos, se asienta en la "servidumbre voluntaria" del mayor número en vez de en la fortaleza del tirano, representado por la sociedad de masas y el Estado burocrático. Un período mínimo de desobediencia voluntaria podría deponer al tirano (democrático). Pero la nueva cadena de dominación, en diferentes niveles jerárquicos, y la red clientelar de favorecidos por el régimen, recién emergidas, lo hacen invulnerable para los dominados ${ }^{15}$. El punto de fuga, para estos nuevos ilustrados, respecto de este nuevo dominio es la amistad (la misma tenida entre Montaigne y La Boétie con pleno uso de las prácticas clásicas) ${ }^{16}$. Una relación entre amigos que Tocqueville expresó nostálgico, sobre todo, en la dilatada correspondencia con Louis de Kergorlay. La correspondencia íntima entre ambos amigos repasa los incidentes de la vida de dos jóvenes -la relación con la familia, los titubeos en la elección de profesión, las ambivalencias de una relación amorosa estable con una mujer cuando se está en plena maduración espiritual...- y prepara un tipo de carácter opuesto a la sociedad de masas entonces emergente. A la muerte de Tocqueville, su más constante y, quizás, mejor amigo no duda que el espíritu público de sus ideas no debe dejar pasar la consideración de un estilo literario que ha apreciado como amigo. Cada palabra dentro de su "gran estilo" se incorpora a un lenguaje digno y cuidado. Le interesa tanto la forma como a los artistas, aunque haya usado la pluma dentro de un compromiso público. Tocqueville, como los antiguos, está dando a su amigo lo mejor porque sólo su excelente corresponsal es capaz de apreciar un estilo inimitable e irreductible al modelo de Montesquieu ${ }^{17}$. A sus veintitrés años, Tocqueville considera la amistad como bien de máxima significación en este mundo. Muestra todo su estupor a Louis de Kergorlay porque haya quien puede vivir sin un solo amigo. Si otros pueden vivir sin amistad -le dice-, no deben valer gran cosa moralmente (Versalles, $7 / I X / 1828)^{18}$. De ahí que la correspondencia de Tocqueville sea sumamente importante para observar la urdimbre de 
sus observaciones. En realidad, por momentos, Kergorlay parece aportarle un método de trabajo a Tocqueville que haga acopio de las costumbres de un pueblo a través de la observación directa. Indudablemente, es el amigo severo de Tocqueville que acude a los clásicos -de Sócrates a los estoicos o a Luciano de Somosata- para resistir como un loco incomprendido, frente a un espíritu moderno que se ha vulgarizado y al que ninguno de los dos desea parecerse. La propia vida afectiva ha de limitarse. Elegir una mujer adecuada es básico para no verse coartado en la auténtica vida del espíritu ${ }^{19}$.

Los primeros análisis muy titubeantes sobre América -sus incipientes comentarios nada más arribar- pueden ser comentados a un amigo al que se conoce tanto que no se teman sus interpretaciones. Tocqueville escribe a Kergorlay, forzado a desbrozar su reflexión por obligación, sus primeras impresiones el 29 de junio de 1831 desde Yonkers. Cauto con la pregunta de su amigo acerca de si había allí unas creencias, Tocqueville se siente interpelado y resalta cómo la inmensa mayoría de los espíritus se reúnen en torno a unas "opiniones comunes". El futuro autor de La democracia en América resalta tres de estas opiniones compartidas: la república es una idea indiscutida; la sabiduria y perfectibilidad humana es digna de fe; la bondad de la instrucción general es de una confianza indiscutible en América y resulta más cuestionada en Francia. "Eh aquí, mi querido amigo, -dice- lo que yo Ilamaría las creencias de este país. Creen de buena fe en la excelencia del gobierno que les rige, creen en la sabiduria de las masas con tal de que estén esclarecidas; (/) y no parecen dudar de que haya una cierta instrucción que no puede ser compartida con las masas jamás y que, sin embargo, puede ser necesaria para gobernar un Estado. En cuanto a lo que nosotros entendemos generalmente como creencias, antiguas costumbres, antiguas tradiciones, potencia de las costumbres, nunca he visto hasta el presente rasgo alguno (...)"20. La pretendida tolerancia norteamericana no es, en su opinión, más que indiferencia. En América, los predicadores sólo tratan lugares comunes de la moralidad -observa Tocqueville- y no cabe que unos y otros se ofendan entre sí. Mientras que Francia posee unos predicadores que ponen en juego tiempo, esfuerzos y fortuna en la pasión religiosa, o cuenta con unos brutos, que no quieren ni oír hablar siquiera de la religión y no disciernen entre el bien y el mal, América -le explica Tocqueville a Kergorlay- carece de estos tipos sociales extremos entre la masa protestante. En América, observa Tocqueville, los instintos religiosos y antirreligiosos se manifiestan con plena libertad. A este estado, Tocqueville le concede categoria de "curioso espectáculo": hay, por otro lado, dos principios que dividen el mundo político. El primer principio lo forman los protestantes de todas las comuniones, practicantes e indiferentes que viven al día, habituados a un medio poco satisfactorio si bien tranquilo donde se cumplen todas las convenciones. No se preocupan del fondo de las cosas en toda su vida y tampoco se reclutan. Por encima, como segundo principio, están los católicos. Usan la tolerancia de sus adversarios pero se mantienen intolerantes como siempre en el sentido de qué creen. Sólo creen en una verdad y fuera de ella está la condena eterna. Viven en medio de la sociedad civil pero se prohiben cualquier relación con las sociedades religiosas que les rodean. Guardan, posiblemente, -observa Tocqueville- el mismo dogma sobre la libertad de conciencia que en Europa y perseguirian a sus adversarios si fueran más fuertes. Los católicos son pobres, llenos de celo, y sus sacerdotes creen en el culto del sacrificio que abrazaron. A diferencia de los sacerdotes protestantes, los sacerdotes católicos no son industriosos en materia de religión. Tocqueville constata el aumento prodigioso de los católicos en Estados Unidos. El autor de La democracia en América no se detiene en constatar la vivencia difusa y leve de la religión protestante sino que experimenta un fenómeno parecido entre la clase dirigente. Los unitaristas, que niegan el misterio de la santísima trinidad y llegan a valorar la figura de Cristo como la de un filósofo semejante a Sócrates -asegura Tocqueville- no tienen de protestantes más que el nombre. Conservan unos ritos ligeros -a los que el gran viajero ha acudido- y mencionan la Biblia para no chocar con el protestantismo. Su aumento de seguidores -observa- es comparable al del catolicismo pero sus seguidores se prodigan entre las clases altas de la sociedad ("rangos altos de la sociedad"). Tanto el catolicismo como el unitarismo se benefician de las pérdidas del protestantismo. La observación tocquevilliana acerca del unitarismo es importante: el protestantismo frío y lógico de las clases discutidoras adquiere en esta manifestación unitarista forma de secta filosófica para los intelectuales, que pasan a hacer profesión pública de su deísmo. Las observaciones provisionales de Tocqueville a su llegada al nuevo mundo no quiere que sean tomadas como absolutas. Le confiesa a Kergorlay que estas observaciones marcan la "tendencia evidente de los espíritus" pero no el estado actual completo en los Estados Unidos. Acaba de llegar a

ARBOR Vol. 187750 julio-agosto [2011] 677-690 ISSN: 0210-1963

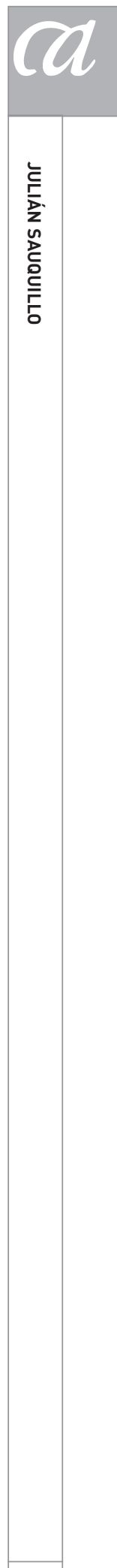


una nación que guarda el más amplio fondo de religión cristiana del mundo. Esta disposición protestante dota de un sesgo moral y dirige las ideas -según su opinión- con indudable influencia sobre el régimen político. Por más que el catolicismo no eligiera caminos al margen de la moralidad y que chocaran abiertamente con las creencias religiosas, el protestantismo se le muestra más flexible a Tocqueville. El protestantismo es innovador sin la pasión que vence todos los obstáculos propia del catolicismo ${ }^{21}$.

Las propias leyes son vistas por este fascinado viajero como causa de la igualdad. Al comienzo de la Revolución -observa Tocqueville- existía igualdad política pero no económica entre los colonos. Las leyes inglesas de primogenitura estaban vigentes, constata Tocqueville. Como consecuencia, en su análisis, no había una clase de nobles pero sí de grandes propietarios que hacian una vida simple y muy intelectual, con un tono de distinción y maneras elevadas propio de familias con un punto de honor. Al establecerse un reparto igual de las herencias, en vez del destino de tres cuartas partes de la fortuna al primogénito, la ley -en el argumento tentativo de Tocqueville- causó un cambio mágico: la tendencia aristocrática de los primeros años de la república fue sustituida por un espíritu democrático imparable. No hay tendencia aristocrática en Estados Unidos, la democracia -según Tocqueville- se extiende a todos los Estados en las costumbres, las leyes y la opinión mayoritaria. Tocqueville constata una extensión de los derechos electorales a todos, sólo negada a algunos vagabundos. El diagnóstico no deja de ser exultante porque atiende a una idea común, uniforme, en los hombres y en las leyes. Pero, ¿qué ocurre con las mujeres o con los negros esclavizados? Lo ignora. La democracia es ilimitada y, buena o mala, es, para Tocqueville, irresistible. Para este extraordinario observador, el movimiento democrático es concluyente, también, para Francia: los Borbones, en lugar de reforzar el principio aristocrático, debieran dar orden y estabilidad a la democracia. Tocqueville tiene reservas hacia el gobierno de la multitud, tiene discrepancias con un gobierno que pretende satisfacer todos los intereses en vez de los intereses más racionales dirigidos por "las clases más esclarecidas y más morales de la sociedad", pero está pensando en la ley como "único contrapeso posible" a la imparable democracia. La satisfacción de los norteamericanos es universal e inimaginable por su amigo -según le manifiesta a Kergorlay en su correspondencia- que no ve esta emergencia de la democracia con sus propios ojos.
Para Tocqueville, la posición moral del pueblo es más elevada en Estados Unidos que en Francia, como más fácil es el sentimiento de cada individuo de su posición y de la importancia de respetar a los otros. La admiración del viajero comprende dos logros extraordinarios. En primer lugar, el respeto por la ley, ya que la hacen ellos mismos y la pueden cambiar. Es más obedecida porque su origen es popular. La segunda cuestión envidiable en este pueblo es la implicación del pueblo en el gobierno. Todos y cada uno están concernidos por la seguridad pública y el ejercicio de las leyes. La fuerza pública reside en todos -observa fascinado- y no está localizada en la policía. Le sorprende a Tocqueville cómo el orden se mantiene porque el pueblo sabe que es su propia salvaguardia. Pero acaba de pisar territorio norteamericano. Se pide, por ello, ante su amigo, un repliegue sobre sí mismo para no dejarse llevar por una fascinación por Estados Unidos que cala en los espíritus lógicos y superficiales. La democracia que está descubriendo sólo puede ser aconsejable para una gran nación a condición de que guarde "un gobierno interior fuerte y una política exterior fija"22.

Frecuentemente, en la teoría social de Tocqueville, se han resaltado aspectos de valedor de una sociedad autorregulada por un supuesto predominio absoluto de la vida política local. Ambos suponen que surge un Estado centralizador y un individualismo egoísta, apropiado a la desaparición de los cuerpos intermedios, sólo cuando la sociedad padece de desintegración. No se obvia la ineludible existencia de un poder externo, pero el acento final se pone en la capacidad de los hombres para autogobernarse. Tocqueville resultaría ser así un anti-Hegel ${ }^{23}$. Pero el autor de La democracia en América confía, muy al contrario, en que la corrección de la inconveniente centralización administrativa venga de un "arte" político centralizado que tuerza esta pésima tendencia de la sociedad moderna. Aunque el énfasis en la participación política descentralizada es cierto, Tocqueville otorga, siguiendo la tradición política clásica, un papel decisivo a la centralización gubernamental -de la que sí es partidario- y al consiguiente liderazgo elitista, en la materialización de esta particular intervención política en la sociedad. Tan importante es la libertad de asociación, para Tocqueville, como la selección de élites y técnicos en el gobierno representativo. En una sociedad atomizada, las asociaciones contrapesan la débil presencia de las demandas individuales. Una presencia casi inexistente en comparación con el paternalista peso del 
Estado. Pero existe una distancia manifiesta entre el origen de la soberanía democrática y su ejercicio efectivo en la democracia representativa. La vida pública está abierta a todos, según diversos niveles adecuados a las diferentes aptitudes y capacidades. Si bien, más allá del gobierno local, la soberanía popular sólo interviene en la elección y control de los representantes ${ }^{24}$. La interpretación de Mill de La Democracia en América se basa en que existe aquí una "distinción capital entre delegación y representación". Además, ambos comparten idéntico pesimismo sobre los procesos de racionalización: el liderazgo político está bloqueado por la homogeneización moderna de los individuos y no es evidente que la democracia impulse la libertad de expresión. Pero Mill es dos puntos más optimista sobre las posibilidades de la democracia: no ve mal endógeno en la falta de cultura dirigente en Estados Unidos, cabe educarla y seleccionarla entre la "clase ociosa"; y atribuye el embelesamiento cultural por la prosperidad económica de la civilización y no a la democratización. En todo caso, ambos denunciaron la asimilación cortesana de los intelectuales al orden imperante y el rentable adocenamiento de la mayoría a la cultura de masas como males endémicos de la democracia emergente. "El hombre de genio se hace cada vez más raro -señala Tocqueville- y la cultura más común". Y, a la vez, celebraron la profundización del Gobierno popular, mayor garantía frente a los "intereses oscuros", adolecidos en la actividad política.

Tocqueville sí es un antiMacintyre, pues piensa que la fragmentación que observa de la sociedad moderna es propia de la sacudida de un paradigma histórico -el premodernoirremisiblemente superado. Más allá de cualquier "ironismo escolástico", muestra un esfuerzo sincero -inútil es añorar la caduca comunidad bien ordenada- por remontar los males que ya le parecen inevitables de la democracia: la homogeneización normalizadora por el disfrute 0 aspiración al bienestar, la pérdida de cualquier estima hacia el noble esfuerzo espiritual y, sobre todo, el riesgo de "inmovilismo chino" entre los ciudadanos y de ejercicio de un "despotismo asiático" venido de las alturas. Destino común a Rusia y a Estados Unidos - para asombro de Schmitt, ya aisladas como las dos superpotencias futuras por Tocqueville-. En un país como Estados Unidos, donde el acceso a las fortunas intermedias y su expansión está generalizado, el poder de las mayorias no se ejercerá sobre las riquezas de unos pocos sino sobre las opiniones disidentes y las minorias de raza y religión. Para Tocqueville, la terapia democrática consiste -y aquí coincide con Mill y Weberen la profundización de la educación política a través de la revitalización del asociacionismo y el quebrantamiento de la opinión pública por las élites democráticas.

\section{EL BIENESTAR MODERNO ACABA CON LA LIBERTAD ANTIGUA}

Tocqueville se atribuye la aceptación de la igualdad de condiciones -las naciones mantendrán indefectiblemente este estado- y se arroga la crítica de la servidumbre acarreada por la pérdida moderna de la virtuosa libertad aristocrática. Vislumbra que las condiciones sociales americanas -igualitarias por económicamente abundantes- son el futuro del viejo continente. Pero no hay que olvidar que es representante genuino del liberalismo -antisocialista y refractario al obrerismo, en Francia, a diferencia de Mill en su segunda etapa, en Inglaterra-, y reflexiona en el centro de convulsiones populares destructoras de los deficientes límites burgueses del contrato liberal. Su conservadurismo le impide reconocer este déficit de legitimación en la sociedad que irrumpe. $Y$, no obstante, su virtualidad critica diagnostica que la desaparición de la sociedad aristocrática supuso la ausencia de sus fuertes virtudes, sin que el estado social democrático haya procurado aquello que pudiera aportar la igualdad social. La fuerza de la minoría fue sustituida por la debilidad de todos. Pero no cabe vuelta atrás en este movimiento moderno traído por la Providencia. El mayor obstáculo a la dinamización de la democracia es la hipostatización de un humanismo burgués que no reconoce otro movimiento que aspirar a los pequeños negocios económicos.

François Furet ha fijado, precisamente, la actualidad de Tocqueville en la manifiesta incompatibilidad entre bienestar y libertad que viene caracterizando a nuestro sistema democrático como deficitariamente legítimo. $\mathrm{Ni}$ la disidencia ni la participación vienen a coincidir con un pacto mayoritario en torno al bienestar igualitario ${ }^{25}$. Sobre el terreno, en Estados Unidos, Tocqueville le escribe a Chabrol: para la sociedad americana, "el interés es el único secreto (...) Estamos aquí muy lejos de las repúblicas antiguas, ¿no es verdad? (...) Lo que conduce a los hombres a enturbiar al Estado es, por un lado, las ganas de conseguir el poder, de otro, la dificultad de formarse una existencia

ARBOR Vol. 187750 julio-agosto [2011] 677-690 ISSN: 0210-1963 
feliz por medios ordinarios. Aquí, en absoluto hay poder público y, hablando en serio, no hay necesidad de él" (10 de junio de 1831). Y su amigo Gustave de Beaumont -con quien viaja a América y completa la descripción del costumbrismo americano- cuenta a su madre: "Vivimos en un país que no conoce en absoluto, desde hace mucho tiempo, las disensiones civiles y políticas. En verdad, no hay más que un partido en América; las disputas que se avivan en los periódicos o en la sociedad son más bien relativas a las personas que a las cosas. Hay que subrayar que los empleos públicos más elevados son poco buscados; aquí sólo hay una cosa que excita vivamente las ambiciones, es la riqueza. Solamente la fortuna da crédito, consideración, poder; los empleos públicos, que son poco retribuidos, no dan ni consideración, ni poder, ni crédito; por lo que no son solicitados más que por los que no tienen nada mejor que hacer (...)" (Nueva York, 7 de junio de 1831)26. Pese a estas malas condiciones sociales -el interés particular aparece como el único móvil para la escasa pasión política-, Tocqueville quiere para su historiografía una función normativa. Frente al determinismo histórico de los historiadores en democracia -partidarios de la obediencia ciega e inflexible a los acontecimientos-, Tocqueville desea, a la manera antigua, enseñar a mandar. Considera que, en todo período político, las grandes personalidades políticas desarrollan la historia en un sentido o en otro. Gobernarse a sí mismo y gobernar a los otros rompe la inexorabilidad de las leyes generales de la historia. El mayor obstáculo democrático a este liderazgo político es el establecimiento de la "humanidad" en la mediocridad y el bienestar. El apagamiento de la juventud y la imaginación, la pérdida de cualquier extremo, el aislamiento de los disidentes y el debilitamiento cortesano de los mayores talentos son efectos de este nivelamiento social democrático. Tocqueville puede ser interpretado en clave de antihumanista y antiburgués.

La vida asociativa y una "doctrina del interés bien entendido" habrian de contribuir a la selección democrática de élites. Pero, aunque éste sea el móvil último de su teoria política, Tocqueville observa en Estados Unidos un predominio vacío de la partitocracia en el poder sólo contrarrestrable a través de otras asociaciones. Una gran desconfianza popular hacia los grandes talentos y el servilismo de los elegibles respecto de los electores procuran un fracaso absoluto en la selección popular de élites: sólo el Senado, mediante un segundo grado de elección, propicia la honorabilidad de los debates parlamentarios americanos. Tocqueville atisba una crisis en el sistema americano de partidos -análisis proseguido por Bryce, Ostrogorski y Weber-, provocada por la proliferación de "pequeños partidos" que nunca representan el interés público y ahogan la actividad franca y audaz de los "grandes partidos".

Tocqueville alentó en la primera parte de La Democracia en América un buen augurio sobre la descentralización administrativa americana y su impulso local. Cinco años más tarde, el acento último recae en el predominio de la weberiana dominación legal-racional, sin que haya determinado un resorte claro de selección de las élites culturales democráticas, fundamentalmente valoradas en su teoría política. El sentimiento igualitario tiene su correlato en la dominación democrática de un poder único y central y una legislación uniforme. El temor al desorden y el amor al bienestar favorecen el predominio absoluto del poder central en manifestaciones cada vez más amplias de la acción social. La destrucción final de todos los poderes secundarios consagra así el despotismo administrador y el predominio de un individualismo atomizado y políticamente estéril. Tocqueville concluye diciendo: "la igualdad sugeria la noción de un gobierno único, uniforme y fuerte. Acabo de mostrar cómo también les habitúa a él; asi que es hacia un Gobierno de ese tipo al que tienden las naciones en nuestros días. La inclinación natural de su espíritu y de su corazón a él les conducía y, para alcanzarlo, les basta con no ponerse límites. Creo que en la era democrática que se inicia, la independencia individual y las libertades locales serán siempre un producto del arte político. La centralización será la forma de gobierno natural"27. La segunda parte de La Democracia en América señala un giro hacia el reconocimiento del auge centralizador. En el año 1835 , le había preocupado la concentración popular y legislativa del poder, ahora la creciente acumulación del poder del Estado y su burocracia ${ }^{28}$. Tocqueville ha oscilado entre el postulado de las grandes virtudes aristocráticas de Plutarco, la reivindicación del honor antiguo en las naciones modernas, y un pesimismo pascaliano sobre el futuro de la libertad en las sociedades democráticas ${ }^{29}$. La absolutización del consensus democrático es el único devenir real y horizonte individual en la historia. El "hombre democrático" desconoce que es más objeto que sujeto del proceso de igualación. Ante la absolutización de las virtudes morales universales, la libertad aparece como un don extraño al "hombre democrático"30. 
El postulado filosófico-político de Mill y Weber puede ser hoy interpretado como una terapia de urgencia a las aporías de la política moderna, no exenta de titubeos en su afirmación democrática. Weber sobrevaloró la democracia plebiscitaria sobre la democracia parlamentaria ${ }^{31}$. De Mill no hay que olvidar que su compromiso socialista, querido como profundizador de la democracia ${ }^{32}$ y su obrerismo estuvo teñido por su teoría del voto plural, matiz de su sufragismo. Mill había percibido ya el posible éxito de la estrategia electoral del movimiento obrero propugnada por Marx y Engels: el auge de los trabajadores manuales, en cuanto población, concluiria en una legislación favorable a la clase obrera. De aquí que propugnara el favorecimiento numérico de los más preparados culturalmente, bajo la intención declarada de favorecer la imparcialidad de las instituciones democráticas. No cabe reconstruir -tal como hace Berlin- la filosofía política de Mill sobre las élites a través de Sobre la libertad (1859) sin aludir a Del gobierno representativo (1861). Es cierto que -tal como señala Berlin- Mill fue un crítico corrosivo de la "religión sin teología" de Comte. No compartía ni su afán reglamentista, ni su deseo -de imponer un altruismo perfecto sobre cualquier tendencia personal. La solidaridad querida por Mill no debería surgir de la paralización de las pasiones e inclinaciones egoístas por la fortificación habitual de las afecciones sociales. La descripción que Mill hace, en 1865, de la transición del anarquismo al positivismo puritano, prevista por Comte, es burlesca ${ }^{33}$. Pero del santsimonismo le hace un encarecido elogio a Gustavo d'Eichtal cuando aprueba la regeneración y desarrollo de la sociedad que está emprendiendo este movimiento "á la téte de la civilisation" (30 de noviembre de 1831). De forma mucho más precisa que Berlin, Macpherson resalta el temor de Mill a un gobierno de trabajadores. Finalmente, la predicción de Bentham y James Mill de que el sufragio universal no favorecería tal gobierno, y la clase trabajadora seguiría el ejemplo de la clase media, acabó confirmándose cuando, muerto Mill, se introdujo el sufragio universal de los varones ${ }^{34}$. Más cercano al fourierismo que al comunismo, Mill objetaba al socialismo revolucionario su tendencia a estrangular la opinión minoritaria en aras de la decisión colectiva y a precipitar los necesariamente paulatinos cambios históricos ${ }^{35}$. Del gobierno representativo prioriza, claramente, el liderazgo de los más capaces e inteligentes y se opone a una posible legislación de clase (trabajadora). Pero su terapia al sedentarismo de las instituciones politicas modernas determina un paradigma reformador del que no hemos salido.

Mill fija en la selección de las élites la salida a los dos males de la política moderna: inexistencia de educación política y burocratización de las decisiones colectivas. La complejidad de la acción social determina en Mill -como en Weber- la disposición de las decisiones públicas por el aparato institucional. La determinación de las funciones del político y del funcionario delimita, tanto en uno como en otro, el ámbito de la imaginación de fines colectivos y de la ejecución de órdenes, respectivamente. Además, ambos conciben el Parlamento como el órgano deliberativo capaz de seleccionar a las élites. Así, Mill señala, en expresión clave que Weber suscribiría: "La enfermedad que afecta a los Gobiernos burocráticos, y de la que ordinariamente perecen, es la rutina. (...) se necesita un régimen popular para que las concepciones de los genios originales tengan probabilidades de prevalecer sobre el espíritu inerte y hostil de las medianías que no ignoran la tradición pero carecen de ciencia (...)"36. Esta "glorificación del genio", como individuo activo y original, realizada por Mill, es un precedente de la noción moderna de carisma radicalizada por Nietzsche. Para Mill el genio posee una capacidad estimuladora de la inteligencia media de los individuos ${ }^{37}$. En cambio, en la formulación del genio realizada por Nietzsche, en Sobre el porvenir de nuestras escuelas (1872), el hombre superior surge en el sacrificio plurisecular de las capacidades de la medianía de la sociedad.

Pese a que la teoría de la personalidad y el politeismo valorativo nietzscheano sean transfondo de la teoría del liderazgo político weberiano ${ }^{38}$, Weber no comparte esta concepción del sacrificio colectivo a la voluntad del líder. El líder carismático ha de impulsar el bien común o la economía política de la nación alemana. Pero su concepción del carisma ha perdido la confianza de Mill en la capacidad desarrolladora del espíritu, procurada por el gobierno representativo. Weber hizo extensivo el sufragio al conjunto de la nación alemana, a través de su contribución personal en el artículo 41 de la Constitución de Weimar. Pero el liderazgo político weberiano supone una alternativa agónica al pesimismo de Tocqueville acerca de las posibilidades de superación de la centralización del poder y la universalización del cálculo individualista. Tocqueville y Weber compartieron la confianza en la iniciativa económica privada para sustituir las estructuras 
económicas tradicionales. Pero su reverso despotenciador del espacio público de la política no es lamentado por Weber, pues habrá de colmarse con la especificidad de la labor del político, definitivamente operada por la división social del trabajo. La Democracia en América plantea la tensión weberiana entre la dominación legal-racional y la dominación carismática. Superada irreversiblemente la dominación tradicional, los últimos restos de elementos carismáticos se encuentran en las virtudes nobles del ocaso social aristocrático. Para Tocqueville prevalecerá, en el futuro, un horizonte cerrado para la política activa, cuya posible superación no vendrá determinada por la dinámica universal de la historia. Weber es heredero de esta aportación práctica de Tocqueville y Mill, sobre la que construye una teoría política definida por la teoría de la dominación, de la burocracia y del liderazgo. La definición weberiana del Estado y de la actividad política, ofrecida en "La política como vocación" (1919), no deja ningún margen a un modelo desarrollista de democracia: "(...). Estado es aquella comunidad humana que, dentro de un determinado territorio (el 'territorio' es elemento distintivo), reclama (con éxito) para sí el monopolio de la violencia física legítima. (...)." Weber se revela, en "Parlamento y Gobierno en una Alemania reorganizada. Una crítica política de la burocracia y de los partidos" (1918), como un representante de primer orden del modelo democrático competitivo de partidos: "la esencia de toda política es luchar, ganarse aliados y seguidores voluntarios (...)", a lo que añade: "(...) para el liderazgo político, en todo caso, sólo están preparadas aquellas personas que han sido seleccionadas en la lucha política, porque la política es, en esencia, lucha.(...)". Aron, en un importante artículo -"Max Weber et la politique de puissance" (1964)-, analiza esta Machtpolitik que Weber reduce al ámbito del Parlamento $y_{1}$ consecutivamente, a la liza internacional, atribuyéndola no supeditarse ni al derecho ni a una ética universal. Efectivamente, Weber, como descendiente de Maquiavelo y Nietzsche, no se pregunta qué régimen es justo: sitúa la lucha en el centro del papel que cada nación ha de ocupar en el ámbito internacional. Para Aron, el combate estipulado, por Weber, para la política entre naciones, clases 0 individuos, se encarna tanto en el parlamentarismo como en el nacionalismo imperialista alemán. Aron subraya este último como el auténtico demonio del sociólogo alemán que, unido a su confianza en el líder carismático, plebiscitariamente elegido, acabaría situándose en la pendiente del nazismo que hubiera deplorado. Para demostrar su tesis se limita a analizarla en el ámbito de las relaciones internacionales. Atribuye a Weber lo que corre, por su crítica del parlamentarismo, más rigurosamente por cuenta de Carl Schmitt. Weber sería así el artífice de una teoría sociológica singular y de una teoría política marcadamente atroz y caduca.

Pero, muy al contrario, su interpretación parlamentaria nos sitúa ante uno de los horizontes más dinamizantes de la política contemporánea. Una moralización de la vida política de alcance social, caracterizada por transformaciones profundas, la organización y la participación de base, auspiciada por el espartaquismo era, para Weber, una provocación a su persona y un desconocimiento vehemente de la responsabilidad del político. El ámbito más restringido de moralización weberiana de la política es el de los políticos profesionales. El gran obstáculo histórico de la política weberiana es la falta de liderazgo político en una nación vaciada de educación política por Bismarck, artífice de una política unipersonal movilizada por una corte de políticos que preservan el "monopolio de

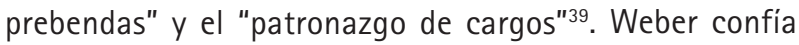
en que la reforma del artículo nueve de la Constitución alemana posibilite la selección del Gobierno en el Parlamento: "(...). El objetivo de una parlamentarización es convertir al Parlamento en un lugar para seleccionar dirigentes. $Y$ un dirigente político no aspira al cargo ni a un sueldo que le permita después una pensión ni tampoco al ejercicio de unas competencias lo más libremente posible, sin controles, sino que aspira a un ejercicio político, y esto quiere decir, a un poder responsable políticamente apoyado en la confianza y en la clientela de un partido, en cuya cúspide o en su centro debe desear permanecer, como ministro, para influir en él (...)" ${ }^{40}$. Sin esta dirección política, parlamentariamente seleccionada, no cabe gobierno de aquello que, para Tocqueville, por futuro político inevitable, requeriría del dominio de un auténtico arte político. Ambos ven un porvenir caracterizado por un dominio burocrático común a todo signo político. Tocqueville reparte su escasa confianza terapéutica en la influencia ejercida entre organizaciones horizontales y verticales; Mill y, sobre todo, Weber confían en una dirección vertical. En todo caso, no les caracterizó la confianza sino, más bien, la animadversión hacia las soluciones que les pudieran llegar de sus conciudadanos medios, bajo la fórmula, acuñada por Tocqueville, de "tiranía de las mayorías". 


\section{UNA TRAGEDIA POLITICA}

Tocqueville y Mill, a mediados del siglo XIX, representan un pathos todavía ambivalente entre el mundo premoderno y el mundo moderno. Son figuras cuyo pensamiento recorre tanto la asunción de la democracia como la nostalgia de un mundo premoderno. Con la cabeza, son demócratas, $y$, con el corazón, liberales, añorantes de una sociedad de caballeros antiguos. Más de medio siglo después, en la República de Weimar, Weber -como Meinecke o Mann- se sitúa entre aquellos que vinieron en llamarse "republicanos de cabeza". Intelectuales que asumen la república friamente, fruto de un compromiso cerebral reflejo, todavía, de una tensión social entre aristocratismo irracional y democristiano racional. "El Estado nacional y la política económica" (1895), de Weber, plantea una severa identificación de la clase social más apropiada al liderazgo económico y político de la nación alemana, decidida, con dificultades, por la burguesía. En opinión de Weber, la clase dirigente habria de ser portadora de la conciencia económica de la nación. La tradicional aristocracia rural prusiana languidece y es pusilánime para representar a la economía política de la nación alemana. El proletariado carece de instinto nacional de poder y energía catilinaria de la acción. Weber sitúa las escasas esperanzas futuras de liderazgo de clase en la burguesía a la que pertenece: "Yo soy un miembro de las clases burguesas, me siento como tal y he sido educado en sus principios e ideales. Pero el contenido de nuestra ciencia es, justamente, decir lo que no gusta oír hacia arriba, hacia abajo y también a la propia clase. Y cuando me pregunto si la burguesía de Alemania está hoy madura para convertirse en la clase política dirigente de la nación, no me es posible contestar, hoy por hoy, que si (...)". La reflexión política de Weber se dirigió, tras esta programática declaración, a la formación de una teoría política burguesa. El interés weberiano por preservar un ámbito de libertad de la depredación esclavizadora de la burocracia está inserto dentro de la preocupación burguesa por la libertad en el desarrollo capitalista de esa época ${ }^{41}$. Weber guarda distancias con el carisma aristocrático que, vinculado con la democracia corporativa, abriría paso al nacionalsocialis$\mathrm{mo}^{42}$. Aunque sea cierto que la última fase del pensamiento político de Weber es plebiscitaria y no parlamentaria, su formulación de las cualidades del líder es, todavía hoy, la más ácida crítica de la supeditación de la política a meros fines técnicos ${ }^{43}$. La decisión personal creadora, encarnada en el líder, es decisión libre y racional entre fines metafísicos, no supeditados a las condiciones del medio, representadas por el técnico y el hombre de orden. A una vida social dominada por la racionalización y los sistemas burocráticos ${ }^{44}$, Weber opone la fuerza heroica del carisma, basada en una intransigencia de origen puritan $0^{45}$.

Sin embargo, la terapia democrática weberiana no remontó el estancamiento de las instituciones de su época. La profesionalización no vocacional de la política, la confusión de funciones y responsabilidades políticas y funcionariales, la reducción de las asociaciones políticas a empresas que aprovechan los puestos de la Administración para premiar a sus partidarios, el predominio de la política de poder sin fin alguno, la disecación del Parlamento por la disciplina dictada por maquinarias burocráticas de los partidos supeditadas al lider caudillista o la trivialización sentimental del discurso y del debate político, aparecieron como síntomas habituales de la fisiología democrática. La política de Weber acaba asemejándose a una política sustentada en el singular crédito moral del personaje que la postula ${ }^{46}$-como las de Tocqueville y Mill-, mientras todo se derrumba a su alrededor. Ni la entrega apasionada a una causa, ni su orientación responsable, ni la mesura recogida y tranquila ante la decisión brillaron en la política reformista postulada por Weber. Y, sin embargo, se ocupa de regenerar la única política posible en nuestro horizonte futuro. Su antípoda política fue el ideario espartaquista de Rosa Luxemburgo, reflejado en Huelga de masas, partido y sindicatos (1906). Una emocionada apuesta por la prioridad de la valerosa acción obrera de base sobre la organización, en la huelga de masas, que quería convertir a la revolución rusa en parte de la historia social y política de los obreros alemanes. Pero, según Weber, las organizaciones sindicales, de las que era partidario, se perpetuarian en un modelo capitalista. Además, la revolución socialista no traería una destrucción del aparato burocrático sino su reforzamiento. En tanta emoción obrerista, Weber sólo veía una intoxicante ilusión de transformación radical de la sociedad: "Liebknecht -dijo- debía estar en un manicomio y Rosa Luxemburgo en un zoológico"47.

"El socialismo" (1918), de Weber, revoca, ya entonces, tres de los presupuestos fundamentales que habían diferenciado a la política marxista. En primer lugar, la democracia sólo significará, en el futuro, según el canon liberal, inexistencia de desigualdades formales en los derechos políticos de la población. En segundo lugar, las leyes de la historia 
no caminan indefectiblemente, como señalaba la profecía materialista histórica, al advenimiento de la sociedad sin clases. En tercer lugar, la separación del trabajador de los medios de producción es efecto de la complejidad de la vida productiva y no medio de explotación. Aun no satisfaciendo todas las preferencias políticas, el horizonte de la política contemporánea, el nuestro, es weberiano. Pero es difícil opinar que aquellos problemas que, in nuce, diagnosticaron Mill, Tocqueville y Weber hayan sido superados. Es razonable pensar, más bien, que muchos de ellos, los fundamentales, siguen pendientes. Todos ellos no pensaron en criterios regulativos que orientaran la vida social, sino en impregnar a todas las instituciones sociales y a los in- dividuos de una dinamización política que no predominaba entonces ni predomina ahora. Hoy el pesimismo que les caracterizó adquiere rango de patetismo. El mayor cambio habido en la política representativa contemporánea sobre la debilidad originaria de la imperiosa educación política y la selección de las élites, característicos de aquel paradigma moderno, es del orden del salto de la cantidad a la cualidad: aquel predominio de la cultura de masas se expandió en la hegemonía absoluta de la "sociedad del espectáculo" y de la adoración al Becerro de Oro. Del compromiso intelectual y moral de aquellos gigantes ya desaparecidos no me cabe duda. De la urgencia de la reflexión, acerca de los dilemas que abrieron, ni resquicio.

\section{NOTAS}

1 Contamos con la traducción y excelente edición crítica de la obra capital de Tocqueville realizada por Eduardo Nolla: La democracia en América, Madrid, Trotta, 2010, 1358 pp. La edición original canónica es De la Démocratie en Amérique, I (Introducción de Harold J. Laski, nota preliminar de J.-P. Mayer), París, Gallimard, 1961, XL+466 pp. (traducción de Dolores Sánchez de Aleu, La democracia en América, I, Madrid, Alianza Editorial, 1980, 446 pp.); De la Démocratie en Amérique, /I (introducción de Georges Lefebvre y nota preliminar de J.-P. Mayer), París, Gallimard, 1961, 428 pp. (traducción de Dolores Sánchez de Aleu, La democracia en América, II, Madrid, Alianza Editorial, 1980, 290 pp.). Alexis de Tocqueville, L'Ancien Régime et la Revolution, I (introducción de Georges Lefebvre y nota preliminar de J.-P. Mayer), Paris, Gallimard, 1953 (renovada en 1980), 448 pp. (traducción de Dolores Sánchez de Aleu, El Antiguo Régimen y la Revolución, I, Madrid, Alianza Editorial, 1982, 268 pp.); L'Ancien
Régime et la Révolution (fragments et notes inédites sur la revolution), Il (texto establecido y anotado por André Jardin), París, Gallimard, 1953 (renovada en 1980), 448 pp. (traducción de Dolores Sánchez de Aleu, El Antiguo Régimen y la Revolución, II, Madrid, Alianza Editorial, 1982, 294 pp.). Tocqueville, Alexis de, Oeuvres I (edición dirigida por André Jardin, colaboración de Françoise Mélonio y Lise Queffélec), París, Bibliothéque de la Pléiade, 1991, 1675 pp.

2 Emmanuel Joseph Sieyès, Escritos y discursos de la Revolución (Edición de Ramón Máiz), Madrid, Centro de Estudios Políticos y Constitucionales, 1990, 362 pp.

3 Alexis de Tocqueville y Gustave de Beaumont, Système pénitentiaire aux Etats-Unis et de son application en France, suivi d'un appendice sur les colonies pénales et de notes statistiques, I y II, Paris, Librairie de Charles

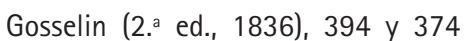
pp. (Estudio preliminar, traducción y notas de Juan Manuel Ros y Julián Sauquillo, Del sistema penitenciario en Estados Unidos y su aplicación en Francia, Madrid, Tecnos, 2005, LXV+ 363 pp.).
Recibido: 7 de marzo de 2011
Aceptado: 17 de abril de 2011 
4 Luxemburgo, Rosa, Huelga de masas, partido y sindicatos (trad. cast. José Aricó, Nora Rosenfeld), Argentina, Siglo XXI, 1970 (2. a ed., 1974), 111 pp.

5 Marx, Carlos y Engels, Federico, Obras escogidas I, II, Madrid, Akal Editor, 1975, 748 pp., 571 pp.

6 Alexis de Tocqueville, De la Démocratie en Amérique, Souvenirs, L'Ancien Régimen et la Révolution, Souvenirs (introducción de Jean-Claude Lamberti), Paris, Robert Laffont, 1986, 1178 рp., pp. 701-892, pp. 758, 769, 770 (traducción de Marcial Suárez; prólogo de Ramón Ramos, Recuerdos de la Revolución de 1848, Madrid, Trotta, 1994, 293 pp.); John Stuart Mill, La Revolution francaise de 1848 et ses détracteurs, Colección de Folletos del Ateneo de Madrid.

7 Raymond Aron, Ensayo sobre las libertades (traducción de Ricardo Ciudad Andreu), Madrid, Alianza Editorial,

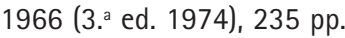

8 John Stuart Mill, Sobre la libertad y comentarios a Tocqueville (edición de Dalmacio Negro Pavón y traducción de Cristina Garcia Gay), Madrid, Espasa Calpe, 1991, 388 pp.

9 Alexis de Tocqueville; John Stuart Mill, Correspondence anglaise, Tomo VI, volumen I, Paris, Gallimard, 1991 (existe traducción).

10 John Stuart Mill, Sobre la libertad (Prólogo de Isaiah Berlin, traducción de Pablo de Azcárate), Madrid Alianza Editorial, 1970, 3.a ed., 1981, 207 pp.

11 Raymond Aron, Les étapes de la pensée sociologique, Paris, Editions Gallimard, 1967, 663 pp. (existe traducción).

12 Carl Schmitt, Ex captivitate salus (trad. cast. Ánima Schmitt de Otero), Santiago de Compostela, Porto y Cia. editores, 1960, 100 pp.
13 François Furet, "Naissance d'un paradigme: Tocqueville et le voyage en Amérique (1825-1831)", Annales, n. ${ }^{\circ}$, marzo-abril de 1984, pp. 225-425.

14 Alexis de Tocqueville, Correspondance d'Alexis de Tocqueville et de Louis de Kergorlay, I (Texto establecido por André Jardin, introducción y notas de Jean-Alain Lesourd), Oeuvres Complétes, XIII, París, Gallimard, 1977, 495 pp., pp. 106-108.

15 Étienne de La Boétie, De la servitude volontaire ou Contr'Un suivi de sa réfutation par Henri de Mesmes (edición y presentación de Nadia Gontarert). Seguido de (presentado por Annie Prassoloff), Paris, Gallimard, 1993, 303 pp.).

16 Anne Dalsuet, "Le texte en perspective", Étienne de La Boétie, De la servitude volontaire (traslación al francés moderno de Myriam Marrache-Gouraud, notas de Myriam Marrache-Gouraud y Anne Dalsuet, dosier de Anne Dalsuet, lectura de imagen de Seloua Luste Boulbina), París, Folio Plus. Philosophie, 2008, 177 pp., pp. 69-177, pp. 136-139.

17 Louis de Kergorlay, "Étude sur Alexis de Tocqueville", Le Correspondant, Paris, abril de 1861, pp. 750-766.

18 Alexis de Tocqueville, Correspondance d'Alexis de Tocqueville et de Louis de Kergorlay, I, op. cit., pp. 143-144.

19 Ibid., p. 348.

20 lbid., p. 226.

21 lbid., pp. 227-231.

22 lbid., pp. 231-235

23 Birnbaum, Pierre, Sociologie de Tocqueville, París, Presses Universitaires de France, 159 pp.

24 Lamberti, Jean-Claude, Tocqueville et les deux démocraties, Paris, Presses Universitaires de France, 325 pp.

25 François Furet, "L'importance de Tocqueville aujourd'hui", L'actualité de Tocqueville, Cahiers de Philosophie politique et juridique, n. ${ }^{\circ}$ 19, Caen, $180 \mathrm{pp}$.

26 Gustave de Beaumont, Lettres d'Amérique 1831-1832 (textos presentados por A. Jardin y G. W. Pierson), París, Presses Universitaires de France, 1973, $221 \mathrm{pp}$.

27 Alexis de Tocqueville, De la Démocratie en Amérique, I/ (introducción de Georges Lefebvre y nota preliminar de J.-P. Mayer), París, Gallimard, 1961, 428 pp.

28 James T. Schleifer, Cómo nació "La democracia en América" de Tocqueville (traducción de Rodrigo Ruza), Méjico, Fondo de Cultura Económica, 1984, 426 pp.

29 Luis Díez del Corral, El pensamiento de Tocqueville, Madrid, Alianza Universidad, $402 \mathrm{pp}$.

30 Pierre Manent, Tocqueville et la nature de la démocratie, París, Julliard, 1982, Fayard, 1993, 181 pp.

31 Joaquín Abellán, "El pensamiento político de Max Weber", Historia de la teoría política (4) (edición de Fernando Vallespín), Madrid, Alianza Editorial, 532 pp., págs 440-468. Mommsen, Wolfgang J. (1959), Max Weber and German politics 18901920 (traducción americana de Michael S. Steinberg), Chicago y Londres, The University of Chicago Press, 1984, 498 pp.

32 Joaquín Abellán y John Stuart, Autobiografía (traducción de Carlos Mellizo), Madrid, Alianza Editorial, 1986, $290 \mathrm{pp}$.

33 John Stuart Mill, Augusto Comte $y$ el positivismo, Buenos Aires, Aguilar, 1972.

34 C. B. Macpherson, La democracia liberal y su época (trad. cast. Fernando Santos Fontela), Madrid, Alianza Editorial, 1981, 150 pp.; Pierre Manent, Tocqueville et la nature de la démocratie, op. cit. 
35 John Stuart Mill, Capítulos sobre el socialismo y otros ensayos (Introducción, traducción y notas Dalmacio Negro Pavón), Madrid, Aguilar, 1979, 174 pp.

36 John Stuart Mill, Del gobierno representativo (Presentación de Dalmacio Negro Pavón, traducción Marta C. C. de Iturbe), Madrid, Tecnos, 1985, 215 pp.

37 Charles Lindholm, Carisma (traducción de Carlos Gardini), Barcelona, Editorial Gedisa, 1992, 303 pp.

38 Wolfgang Mommsen, Max Weber. Sociedad, política e historia (versión castellana de Ernesto Garzón Valdés), Editorial Laia, 1981, 333 pp.

39 Max Weber, El político y el científico (Introducción de Raymond Aron; traducción de Francisco Rubio Llorente),
Madrid, Alianza Editorial, 1967 (7. $^{\text {a }}$ ed. 1981), 231 pp.

40 Max Weber, Escritos Políticos (Edición de Joaquín Abellán), Madrid, Alianza Editorial, 1991, 370 pp.

41 David Beetham, Max Weber y la teoría política moderna (traducción de Fernando Pérez Cebrián), Madrid, Centro de Estudio Constitucionales, 1979, 459 pp.

42 Arthur Mitzman, La jaula de hierro. Una interpretación histórica de Max Weber (traducción de Ángel Sánchez Pascual y María Dolores Castro Lobera), Madrid, Alianza Editorial, 1976, 288 pp.

43 Antonio Valdecantos, "Argumentos weberianos", Claves de Razón Práctica, n. ${ }^{\circ}$ 27, noviembre de 1992, $80 \mathrm{pp}$.
44 José María González Garcia, La máquina burocrática (Afinidades electivas entre Max Weber y Kafka), Madrid, Editorial Visor, 222 pp. Karl Jaspers, Conferencias y ensayos sobre historia de la filosofía (traducción de Rufino Jimeno Peña), Madrid, Editorial Gredos, 1972, 459 pp.

45 Wolfgang Mommsen, "La sociología política de Max Weber y su filosofía de la historia", Presencia de Max Weber (Talcot Parsons y otros), Buenos Aires, Ediciones de Nueva Visión, 1971, 265 pp.

46 Karl Jaspers, Conferencias y ensayos sobre historia de la filosofía, op. cit.

47 Anthony Giddens, Politica y Sociología en Max Weber (traducción de Andrés Linares), Madrid, Alianza Editorial, 1976, 98 pp. 